\title{
EFEITO MEDIADOR DO PERSON-ORGANIZATION FIT NA RELAÇÃO ENTRE PRÁTICAS DE GESTÃO DAS RELAÇÕES INTERPESSOAIS E ÍNDICES DE TURNOVER
}

\section{THE MEDIATION EFFECT OF PERSON-ORGANIZATION FIT ON THE RELATION BETWEEN INTERPERSONAL RELATIONSHIP MANAGEMENT AND TURNOVER INDEXES}

\author{
DANIELLE DEIMLING DE CARLI \\ Mestre em Gestão e Desenvolvimento Regional - UNIOESTE \\ Docente no Serviço Nacional de Aprendizagem Industrial - SENAI \\ Orcid: https://orcid.org/0000-0001-8864-8941 \\ E-mail: dani.carli@hotmail.com \\ JUCELIA APPIO FRIZON \\ Doutora em Administração - UP \\ Docente na Universidade Estadual do Oeste do Paraná - UNIOESTE \\ Orcid: https://orcid.org/0000-0002-2721-4418 \\ E-mail: juceliaappio@yahoo.com.br \\ Av. Júlio Assis Cavalheiro, 1401, apartamento 702, centro \\ Francisco Beltrão-PR - CEP: 85.601-000
}

\begin{abstract}
RESUMO
Este trabalho analisa se Person-Environment Fit tem efeito mediador na relação entre as Práticas de Gestão das Relações Interpessoais e Índices de Turnover dos funcionários nas "Melhores Empresas para trabalhar" no Brasil em 2017. O presente estudo tem abordagem quantitativa de caráter descritivo com corte transversal. Os dados, de ordem secundária, foram fornecidos pela Fundação Instituto de Administração (FIA). Utilizou-se dados de 456 empresas para análise das Práticas de Gestão das Relações Interpessoais e índices de Turnover e das percepções de 250.273 funcionários para os Índices de Qualidade no Ambiente de Trabalho (IQTA). Para efeito de teste do modelo procedeu-se regressão linear, seguido dos testes de Sobel, Aroian e Goodman para efeito de mediação. Organizadas a variável dependente, independente e mediadoras, avaliou-se se o conjunto das Práticas das Relações Interpessoais afetam os índices de Turnover das organizações pesquisadas e tal relação foi confirmada $\left(\mathrm{H}_{1}\right)$, sendo que quanto maior a incidência destas práticas, menores os índices de Turnover. Constatou-se, em seguida, que a existência de Práticas de Gestão das Relações Interpessoais impacta no Person-Environment Fit em três dimensões $\left(\mathrm{H}_{2 a}, \mathrm{H}_{2 b}\right.$ e $\left.\mathrm{H}_{2 c}\right)$. No entanto, com relação ao efeito de mediação das dimensões da variável Person-Environment Fit entre o conjunto das Práticas das Relações Interpessoais e os indicadores de Turnover identificou-se que somente Person-Organization Fit $\left(\mathrm{H}_{3 a}\right)$ pode ser considerada mediadora, rejeitando mediação das variáveis Person-Job Fit $\left(\mathrm{H}_{3 b}\right)$; Person-Group Fit $\left(\mathrm{H}_{3 c}\right)$ e PersonSupervisor Fit $\left(\mathrm{H}_{3 \mathrm{~d}}\right)$. Limitações e sugestões para futuros trabalhos são apresentadas no encerramento deste artigo.
\end{abstract}

Palavras-chave: Gestão de pessoas. Relações interpessoais. Ambiente de trabalho. Turnover. 


\section{ABSTRACT}

This work examines whether the Person-Environment Fit has a mediator effect in the relation between Interpersonal Relationship Management and Turnover Indexes of the employees in the "Best Companies to work" in Brazil, in 2017. The present study has a quantitative approach with a descriptive character and with a cross section. By using second-order data that were provided by the Foundation Institute of Administration (FIA). It was used the data of 456 companies to analyze the Interpersonal Relationship Management and Turnover Indexes and the perceptions of 250.273 employees for the Quality Indexes in the Work Environment (QIWE). To test the model it was used the linear regression followed by the Sobel tests, Aroian and Goodman for a mediation effect. When the dependent, independent and mediator variables were organized, it was evaluated the set of Interpersonal Relationship Practices affects the Turnover indexes of the organizations surveyed and this relation was confirmed $\left(\mathrm{H}_{1}\right)$, whereas the how much more is the incidence of these practices, the lower will be the Turnover indexes. Then it was found that the existence of Interpersonal Relationship Management Practices may cause an impact in the Person-Environment Fit in three admeasurements $\left(\mathrm{H}_{2 a}, \mathrm{H}_{2 b}\right.$ e $\left.\mathrm{H}_{2 c}\right)$. However, in relation to the mediation effect of the variable dimensions Person-Environment Fit among the set of Interpersonal Relationships Practices and the Turnover indicators, it was identified that only the Person-Organization Fit $\left(\mathrm{H}_{3 a}\right)$, may be considered a mediator, refusing the mediation of the variables Person-Job Fit $\left(\mathrm{H}_{3 b}\right)$; PersonGroup Fit $\left(\mathrm{H}_{3 \mathrm{c}}\right)$ and Person-Supervisor Fit $\left(\mathrm{H}_{3 \mathrm{~d}}\right)$. Limitations and Suggestions for the future studies are going to be presented at the end of this article.

Keywords: People management. Interpersonal relationship. Work environment. Turnover.

\section{INTRODUÇÃO}

A partir dos anos 1990 notavelmente a área de Recursos Humanos (RH) deixou de premiar somente sua função de administração de pessoal para abranger a área estratégica das organizações. Deste modo a gestão estratégica de pessoas, como é chamada na contemporaneidade, passou a fazer parte do modelo organizacional que sobreveio a abranger estratégias, políticas, práticas e filosofias de gestão de pessoas (VENTURA; LEITE, 2014).

Atualmente considera-se o desafio de alinhar e compartilhar os interesses dos funcionários como precedente do comprometimento organizacional e a compreensão dos fatores inerentes ao comportamento humano como essência da gestão estratégica de pessoas (VENTURA; LEITE, 2014), sendo que para conduzir os processos organizacionais, deve-se utilizar de análises e instrumentos capazes de identificar, desenvolver pessoas e retê-las, para assim alcançar objetivos (BRANDÃO, 2012).

$\mathrm{O}$ modelo de gestão estratégica tem ganhado legitimidade e credibilidade à medida que demonstra sua efetividade, reforçado por ações, apresentadas na forma de práticas diretivas, estabelecidas por meio de políticas (DUTRA, 2010). Não obstante, a literatura tem evidenciado relações positivas entre a incidência de práticas e políticas de gestão de pessoas e variáveis como comprometimento, desempenho, produtividade e resultado organizacional (GUEST, 2011).

Ao relacionar gestão de pessoas a resultados organizacionais, cabe incluir que performance é um conceito multidimensional. Richard et al. (2009) ponderam sobre a necessidade de discussão acerca do significado e dos métodos de mensuração do desempenho utilizados por pesquisadores da área da administração, sendo que, o uso de 
indicadores únicos ou não adicionados para mensuração do desempenho organizacional em pesquisas empíricas é prática comum e é um demonstrativo dessa fragilidade. Realidade que se agrava, se for considerado a implantação de novos indicadores de performance, tais como o desempenho social ou o desempenho ambiental (MATITZ; BULGACOV, 2011), resultados de RH (ARTHUR, 1994; MCDUFFIE, 1995; TIBOLA, 2012), resultados organizacionais (BECKER; GERHART, 1996; TIBOLA, 2012).

No entanto, o reconhecimento de que o do impacto da gestão de pessoas em performance organizacional tem se tornado um tema relevante de pesquisa (TIBOLA, 2012). Para fins deste trabalho, busca-se a utilização do indicador Turnover de funcionários como relevante para a análise da Performance dos Resultados de RH (ARTHUR, 1994; MCDUFFIE, 1995; TIBOLA, 2012).

Popularizou-se na década de 90, uma abordagem sistêmica com foco em mensurar o desempenho organizacional, abrangendo a aplicação de práticas de forma conjunta e planejada, denominada de High Performance Work Systems (HPWS) ou Sistemas de Trabalho de Alto Desempenho (STAD). Pressupõe-se que a aplicação de práticas de forma conjunta e planejada, que explorem simultaneamente o potencial de complementariedades e sinergias, impactaria em performance organizacionais superiores e em vantagem competitiva (HUSELID, 1995).

A literatura apresenta algumas discussões acerca de quais práticas integrariam as HPWS e quais seus resultados efetivos. Para fins deste trabalho, entende-se que é relevante compreender como as Práticas de Gestão das Relações Interpessoais contribuem com um melhor alinhamento entre pessoas e organizações e de que forma esta relação influencia no índice de Turnover das organizações.

A teoria de Person-Environment Fit (P-E FIT) infere que características individuais podem determinar a capacidade de adaptação de um indivíduo a certa organização e prescrever resultados. O modelo de P-E FIT, neste sentido, pretende delinear uma estrutura capaz de avaliar e prever em que medidas as características do funcionário, em conjunto com as características do ambiente de trabalho, podem determinar a satisfação, a saúde e a bemestar psicoemocional dos mesmos (CHIAPPELI; KUTSCHMAN, 2016). Assim, apresenta-se a pergunta de pesquisa: Person-Environment Fit (P-E FIT) medeia a relação entre as Práticas de Gestão das Relações Interpessoais e o Índice de Turnover dos funcionários nas "Melhores Empresas para trabalhar" no Brasil em 2017?

Justifica-se a inclusão do P-E FIT pois, as pessoas procuram e criam ambientes que permitem manifestar comportamentalmente suas características; à medida que as pessoas se encaixam em seus ambientes de trabalho evidenciam-se consequências significativas, tendose o melhor alinhamento associado à melhores resultados.

Assim, entendendo-se que os relacionamentos são fenômeno inerente à natureza das organizações e aos agrupamentos de pessoas que as integram, contexto o qual, envolve processos comunicativos e todos os seus elementos constitutivos, justifica-se, assim, investigar sua contextualização. Tal contexto, atrelado às peculariedades das gestões modernas e à pergunta apresentada, apresenta-se o objetivo do presente artigo, o qual busca analisar se Person-Environment Fit (P-E FIT) tem efeito mediador na relação entre as Práticas de Gestão das Relações Interpessoais e o Índice de Turnover dos funcionários nas "Melhores Empresas para trabalhar" no Brasil em 2017.

Esta pesquisa de carater quantitativo tem como foco de estudo as empresas participantes do ranking para eleição das "Melhores Empresas para Trabalhar", de 2017, realizado pela Fundação Instituto de Administração (FIA), por meio do Programa de Estudos 
em Gestão de Pessoas.

O artigo é relevante para a literatura, uma vez que sintetiza os resultados atrelados a outras investigações, cabendo como norteador de novos estudos empíricos, e busca contribui para desmistificar os fatores substanciais na permanência de colaboradores em deteraminada organização. Em segunda análise, tem-se de forma prática que as informações destacadas nas análises são relevantes à tomada de decisão de gestores, no que tange ao estabelecimento de práticas organizacionais, elucidando aos mesmos a efeitividade desssa ações.

\section{HIGH PERFORMANCE WORK SYSTEMS (HPWS)}

Para distinguir as perspectivas teóricas implicitas à relação entre as práticas de gestão de pessoas e a performance organizacional utiliza-se do trabalho de Delery e Doty (1996), o qual classifica tais abordagens em: universalista, contigencial e configuracional.

De acordo com estes autores, a perspectiva universalista sustenta a ideia da existência de práticas universais que podem ser implementadas em qualquer organização, independentemente do contexto, seu porte, tamanho e atuação. $O$ estudo mais amplamente citado adotando a hipótese universalista é Pfeffer (1998).

A abordagem contigencial sustenta que a relação entre as práticas de gestão de pessoas e o desempenho organizacional é contingenciada e moderada por vários fatores contextuais externos e internos às empresas, havendo uma relação entre tais variáveis. Assim "quanto mais alinhadas estiverem as estratégias e as práticas, maiores as possibilidades de desempenho superior da organização" (BIANCHI; ALBUQUERQUE, 2011, p. 03). Autores que argumentam por uma abordagem contingencial entendem que pacotes específicos de práticas organizacionais variam de acordo com a atuação da empresa e sua estratégia (ARTHUR 1994), contrariamente à visão universalista, de estilo único, na qual Huselid (1995) desenhou seus resultados.

A abordagem configuracional ampara que a relação entre as práticas e o desempenho da gestão de pessoas é moderada pelas interações entre as variáveis individuais destas práticas. Práticas internamente consistentes que posteriormente seriam alinhadas à estratégia da organização. A ideia é que algumas práticas de gestão de recursos humanos tenham um relacionamento complementar com outras, criando, assim, sinergias que aumentariam o desempenho organizacional (BIANCHI; ALBUQUERQUE, 2011).

A noção de ajuste leva à distinção entre a abordagem das "Best Pratices" e das "Best Fits". Da perspectiva universalista deu-se origem às "Best Practices", sendo que a principal hipótese deste modelo é que existe um conjunto de práticas de gestão de RH que universalmente levam a um desempenho organizacional superior. Baseada nas abordagens contingencial e configuracional, tem-se as "Best Fit", a qual argumenta-se que as estratégias de gestão de pessoas são mais efetivas quando integradas ao contexto específico da organização e de sua estratégia (KAUFMAN, 2010).

Tem-se ainda neste contexto, a dificuldade de identificar-se o elo na corrente causal que relaciona práticas de gestão de pessoas com o desempenho organizacional, o qual passou a ser conhecido como o fenômeno da "black box", pelo fato do conhecimento sobre este conteúdo ainda ser limitado (WRIGHT; GARDNER, 2002; GUEST, 2011). Kaufman (2010) alude esta situação à má especificação metodológica das pesquisas que resultam em variáveis distantes, independentemente de outras influências e explicações alternativas. De acordo com Cardoso (2012), o conceito de "black box" diz respeito aos processos desconhecidos que ocorrem quando os "inputs" são convertidos em "outputs" vantajosos, havendo ainda uma lacuna de conhecimento sobre como se dá essa dinâmica. 
Em virtude das dificuldades em se compreender a relação entre as práticas de gestão de pessoas e a performance organizacional, em meados de 1990 começa a se popularizar uma abordagem que ficou conhecida como High Performance Work Systems (HPWS). Esta abordagem sistêmica tem como foco mensurar desempenho, abrangendo a aplicação de práticas de forma conjunta e planejada. A presunção é que sistemas mais eficazes de gestão de $\mathrm{RH}$ determinam práticas que exploram simultaneamente $\mathrm{o}$ potencial de complementaridades ou sinergias entre estas e ajudam a implementar a estratégia organizacional, sendo fontes de vantagem competitiva sustentáveis (HUSELID, 1995).

Um dos trabalhos mais complexos publicados para identificação das HPWS foi realizado por Phostuma et al. (2013), o qual realizou uma pesquisa bibliográfica acerca da temática. Inicialmente foram selecionadas mais de 10.000 citações. Os artigos foram selecionados devido à relevância sendo que apenas artigos acadêmicos revisados por pares (conceituais e empíricos) e que identificaram múltiplas práticas foram selecionados. Desta seleção, 181 artigos foram usados para codificar diversas práticas de HPWS não redundantes. Estas publicações foram realizadas entre 1992 e 2011, sendo que, 51\% desses estudos eram provenientes de fontes anglo-americanas (Austrália, Grã-Bretanha, Estados Unidos e Nova Zelândia) e $49 \%$ de outros países. Destacam as principais práticas de HPWS, sendo: práticas de recrutamento e seleção, gestão de rotatividade e retenção de pessoas, compensação e benefícios, gestão de desempenho e avaliação, treinamento e desenvolvimento de pessoas, promoção, relacionamento, comunicação e design de trabalho.

Pode-se destacar que HPWS representam uma fonte de ativos invisíveis que tanto criam valor quanto são difíceis de imitar. Estes sistemas produzem conhecimento tácito que é incorporado em indivíduos e práticas. $O$ valor estratégico deste conhecimento se relaciona a sua adequação para a implementação da estratégia em cada nível da empresa. Isso implica em que o aspecto mais importante do ajuste é sua inserção em toda a organização; representa então uma capacidade "invisível" para a implementação efetiva da estratégia organizacional (BECKER; HUSELID, 1998).

Os sistemas de gestão de RH podem ser usados como um meio integrado para melhorar as habilidades, os conhecimentos e a motivação dos funcionários e, assim, cumprir suas obrigações de trabalho e desempenho. Uma vez que os funcionários são qualificados, bem informados, capazes e motivados, eles são mais propensos a responder ao investimento de sua empresa, expandindo mais esforços para realizar seu trabalho. Para este fim, eles farão uma contribuição significativa para os resultados, e assim, ajudarão a empresa para atingir seus objetivos definidos (DO, 2016).

\subsection{PRÁTICAS DE GESTÃO DAS RELAÇÕES INTERPESSOAIS}

As práticas de gestão das relações interpessoais estão conexas às práticas que conduzem o relacionamento entre empregados e a organização. Influenciam diretamente na cultura e no clima organizacional e propõem que ambientes de confiança permitem maior comprometimento e produtividade por parte dos funcionários, e por consequência melhor desempenho da empresa (PHOSTUMA et al., 2013).

No que tange ao universo da gestão de aspectos comportamentais e de valores, cabe ainda, algumas reflexões, visto que tal contexto é pertinente e eminente nesta pesquisa e tem-se como uma variável de análise: as Práticas de Gestão das Relações Interpessoais. Conforme publicado por Mailhiot $(1976$, p. 66) "a produtividade de um grupo e sua eficiência estão estreitamente relacionadas não somente com a competência de seus membros, mas sobretudo com a solidariedade de suas relações interpessoais". Nesta concepção, diversas 
práticas têm sido implementadas e reconhece-se a grande importância da temática tanto para indivíduos quanto para organizações, relacionando-as à produtividade, qualidade de vida no trabalho e efeito sistêmico (COSTA, 2004).

As relações interpessoais consistem em processos de mutualidade, inerente ao convívio humano, tendo-se que em ambiente organizacional naturalmente há trocas de cunho técnico, teórico e até mesmo o compartilhamento de experiências entre as pessoas (FERNANDES et al., 2015). Tendo em vista que o ambiente organizacional se constitui de uma rede de relacionamentos, invoca-se o papel da organização neste contexto, mais propriamente da gestão de pessoas e de suas práticas.

\subsection{PERFORMANCE ORGANIZACIONAL}

A complexidade e multidimensionalidade do conceito de performance dificulta a seleção de um esquema conceitual para defini-la, bem como, a adição de medidas acuradas para operacionalizá-la. Pesquisadores têm conceituado e medido performances de diferentes formas, dependendo das questões da pesquisa, do foco disciplinar e da disponibilidade de dados (PERIN; SAMPAIO, 2004).

Neste sentido, o conceito de performance tem se expandindo, ademais, têm-se encontrado na literatura muitas pesquisas correlacionando o âmbito da gestão de pessoas aos resultados organizacionais (ARTHUR, 1994; MCDUFFIE, 1995; BECKER; GERHART, 1996; GUEST, 2011; MATITZ; BULGACOV, 2011; TIBOLA, 2012).

A questão da rotatividade "Turnover" dos funcionários têm impacto direto sobre os resultados organizacionais, uma vez que os colaboradores detêm o capital intelectual da organização. O contexto que culmina na saída do colaborador da organização acarreta em custos, os quais impactarão em outros indicadores organizacionais. Os resultados organizacionais podem ser afetados por altos índices de rotatividade (FRANCISCO, 2013).

De acordo com Barreto (2014), existem vários custos relacionados à rotatividade dos funcionários, incluindo o custo de substituir o colaborador tanto no mercado interno como no mercado externo, a quantidade de formação que foi investida neste, os custos legais e muitas vezes o custo de desempenho em cargos que exijam um processo mais rigoroso de substituição/formação. Pode-se, desta maneira, inferir que custos de Turnover indiretamente impactam os resultados financeiros organizacionais.

\subsubsection{Turnover}

Turnover é Definido por Marras (2000, p. 66), como "o número de empregados desligados da empresa num determinado período comparativamente ao quadro médio de efetivos". O conceito de Turnover tem sido amplamente utilizado no contexto organizacional nas últimas décadas, entretanto, sua quantificação e seu gerenciamento são ferramentas que ainda não fazem parte da cultura da grande maioria das organizações brasileiras (GONÇALVES; MOLLICA, 2016). Mesmo com a diminuição da previsibilidade organizacional e da estabilidade no emprego, os modelos tradicionais de carreira linear não são mais realidade de muitos profissionais (STEIL, 2011).

A gestão de Turnover é a capacidade que as organizações apresentam de manter grupos específicos de profissionais atuando nelas, de modo a obter seus objetivos estratégicos (STEIL; PENHA; BONILLA, 2016). De acordo com Ribeiro (2005), para reter talentos dentro da empresa, a área de $\mathrm{RH}$ deve criar medidas para estimular e desenvolver o potencial de seus profissionais. Em geral, as companhias que promovem um bom ambiente de trabalho não perdem facilmente os seus talentos. 
Em estudo sobre retenção de pessoas, Chew (2004) apontou que ajustes entre as pessoas e a organização, remuneração, recompensa e reconhecimento, além de treinamento e desenvolvimento de carreira, aliados às oportunidades desafiadoras são práticas que contribuem efetivamente na retenção de pessoas, sendo fatores decisivos para que a escolha em permanecer na organização.

\subsection{PERSON-ENVIRONMENT FIT (P-E FIT)}

O P-E FIT surge da teoria do alinhamento personalidade-trabalho que propõe que características individuais podem determinar a capacidade de adaptação do indivíduo em uma organização e estabelecer sinergia dentro de um ambiente de trabalho. Do seu domínio original, o modelo de alinhamento P-E foi expandido para oferecer uma estrutura capaz de avaliar e prever em que medidas as características do funcionário, em conjunto com as características do ambiente de trabalho, podem determinar a satisfação, a saúde e o bemestar psicoemocional dos mesmos (CHIAPPELI; KUTSCHMAN, 2016).

Tradicionalmente, as origens da abordagem de alinhamento pessoa-ambiente foram traçados por Frank Parsons (1909) que se utilizou da ciência para resolver problemas sociais. Como advogada e educadora progressista, Parsons projetou seu modelo para uso na forma de testes psicológicos que procuravam enfatizar a importância da pessoa e das variáveis de ambiente na escolha vocacional.

Na década de 30, Donald G. Paterson por meio da Universidade de Minnesota usou uma combinação de registros de entrevistas, resultados de testes de aptidão e interesses, bem como de testes de personalidade para diagnosticar as causas de desajuste ocupacional de indivíduos e guiar os desempregados para vagas de emprego que melhor se encaixassem em suas características individuais, experiências e potencialidades. A abordagem orientada por dados de Paterson foi utilizada por Williamson em 1939 para entender e maximizar o alinhamento/ajuste entre a capacidade de um indivíduo e os fatores necessários para o sucesso em seu ambiente de trabalho (SU; MURDOCK; ROUNDS, 2015).

Lewin (1935) elaborou a teoria de campo, que se baseia em duas suposições fundamentais, a de que o comportamento humano é derivado da totalidade de fatos coexistentes e que estes têm o caráter de um campo dinâmico, no qual cada parte do campo depende de uma inter-relação com as demais outras partes. Assim sendo, o comportamento é função ou o resultado da interação entre a pessoa e o meio ambiente que a rodeia. Quando a percepção/opinião do indivíduo sobre o ambiente for positiva tende a demonstrar um comportamento positivo, uma vez que objetos, pessoas ou situações adquirem para o indivíduo uma valência positiva.

Murray (1938) desenvolveu a teoria atrelando-a as necessidades. Uma ênfase deste modelo foi uma tipologia que descrevia diferentes necessidades e as organizava em categorias, tais como se as necessidades conscientes ou inconscientes, ou psicogênica (isto é, fisiológica ou psicológica) e latente ou manifesta (isto é, oculto ou expresso abertamente). Referiu-se, deste modo, a estímulos que podem beneficiar ou prejudicar a pessoa, com base em se os estímulos promovem ou inibem o cumprimento de necessidades (EDWARDS, 2008). Deste modo, o alinhamento P-E foi resumido por Edwards (1996) da seguinte forma: em essência, este ajuste incorpora a premissa de que atitudes, comportamentos e outros resultados de nível individual resultam não da pessoa ou do ambiente separadamente, mas da relação entre os dois (LEWIN, 1935; MURRAY, 1938; PERVIN, 1987).

Em termos práticos, o modelo de alinhamento P-E leva a identificar os pontos-chave da intervenção preventiva para melhorar o contato da realidade da pessoa, a qualidade de 
vida e, em geral, o bem-estar. Em grande medida, a percepção de pertencimento de um indivíduo dentro do ambiente depende de sua capacidade em discernir a percepção da realidade, e poderia ser equiparado à inteligência emocional (GIDDENS, 1987).

A pesquisa sobre enquadramento profissional iniciada por Parsons (1909) cresceu para incluir uma ampla variedade de conceituações do que significa encaixar e a que aspectos do ambiente se encaixam. $\mathrm{O}$ alinhamento/ajuste é geralmente definido por alguma forma de congruência ou correspondência entre a pessoa e o ambiente. Este jogo gira em torno de dois temas básicos: o atendimento das necessidades individuais pelos suprimentos fornecidos no ambiente e as demandas do meio ambiente a serem atendidas pelas habilidades do indivíduo.

Para fins desse artigo e em consonância com o domínio do alinhamento/ajuste do P-E, quatro ramificações foram sendo determinadas, sendo estes, Person-Organization Fit (P-O FIT), Person-Job Fit (P-J FIT), Person-Group Fit (P-G FIT) e Person-Supervisor Fit (P-S FIT) (KRISTOF-BROWN; LI; SCHEIDER, 2016).

\section{Person-Organization Fit (P-O FIT)}

O modelo proposto por Chatman (1989) considerou como aspecto mais importante na determinação do alinhamento P-E a congruência entre valores pessoais dos membros de uma organização e as normas e valores dessa organização; o P-O FIT ou alinhamento PessoaOrganização. De acordo com o autor, o alinhamento P-O FIT pode ser alcançado por meio do processo de seleção, onde as organizações devem recrutar pessoas cujos valores correspondam aos delas. Além disso, Chatman propôs uma socialização, processo através do qual uma organização influencia seus membros e desenvolve seus valores pessoais para um alinhamento com valores organizacionais (SU; MURDOCK; ROUNDS, 2015). O alinhamento PO FIT cria uma identidade organizacional ao estabelecer valores consistentes que permeiam uma cultura organizacional. Assim, o alinhamento P-E FIT equilibra funções nos níveis organizacional e individual (WERBEL; DEMARIE, 2001).

O índice de compatibilidade entre a pessoa e a organização é realizado por meio da combinação de características que estão presentes na organização e na pessoa, cujo grau de aproximação pode apresentar variações, estando muito próximos ou até opostos. O alinhamento suplementar ocorre quando uma pessoa suplementa ou possui características as quais são similares às de outros indivíduos em um ambiente. $O$ alinhamento complementar, quando a pessoa acrescenta ao ambiente organizacional as habilidades ou características que Ihe eram privadas (KRISTOF-BROWN, 1996).

Diversos estudos encontraram relações consistentes e fortes entre P-O FIT e a intenção de Turnover e satisfação no trabalho. Choi e Yoo (2005) encontraram o ajuste do P-O FIT correlacionado fortemente com a intenção de Turnover ( $r=-0.52)$.

Há incidência de publicações relacionando P-O FIT e Turnover. Um estudo empírico realizado no setor hoteleiro da Malásia por Zhen, Mansor e Chong (2019) propôs um modelo conceitual utilizando-se da variável Satisfação no Trabalho para mediar a relação causal entre estes dois constructos. Outro estudo convergente realizado por Ertas (2019) investigou 400 pessoas com cargos gerenciais para examinar as relações de intenção de rotatividade, fatores de motivação, P-O FIT e estado emocional no trabalho. Concluíram que P-O FIT é o principal fator de retenção, enquanto, a falta de oportunidade de crescimento o fator principal de Turnover (ERTAS, 2019).

Para McCulloch e Turban (2007) se faz necessário desde o processo de seleção de pessoas considerar o ajuste P-O FIT, enfatizando se valores e filosofias de ambos são 
compatíveis, pois, evidentemente quando este ajuste é deficiente, o indivíduo tende a deixar a organização e esta situação resulta em custos organizacionais.

Person-Job Fit (P-J FIT)

O P-J FIT, ou alinhamento pessoa-trabalho diz respeito à compatibilidade entre as características de um indivíduo (necessidades psicológicas e biológicas, objetivos, valores, personalidade e habilidades) e aquelas do trabalho que estes irão realizar. É uma correspondência entre um indivíduo e requisitos de um trabalho específico (EDWARDS, 1991). As empresas, muitas vezes buscam essa adequação pessoa-trabalho de modo a adequar o conhecimento e as habilidades do candidato às exigências de vagas de emprego específicas e analisar a capacidade deste em realizar imediatamente sua função sem necessidade efêmera de treinamento.

As operacionalizações comuns do P-J FIT incluem a perspectiva de necessidades e a perspectiva das demandas-habilidades (EDWARDS, 1991), isto é, esta forma de ajuste diz respeito à compatibilidade entre as habilidades do indivíduo e as demandas do trabalho ou as necessidades/valores do trabalho de serem providas no exercício do mesmo.

Existem evidências consideráveis de que um alto nível de adequação de P-J FIT tem vários resultados positivos. A revisão da literatura de adequação da P-J FIT relizada por Edwards (1991) identificou satisfação no trabalho, baixo nível de estresse, motivação, desempenho, participação e retenção como resultados positivamente afetados pelo ajuste de P-J FIT. Quando a adequação de P-J FIT é avaliada como a correspondência entre o que um funcionário quer e recebe da execução de um trabalho, ela está correlacionada a uma melhor satisfação no trabalho, ajuste e comprometimento organizacional, além de reduzir as intenções de desistir. Benefícios adicionais para o desempenho de tarefas foram demonstrados quando a definição de ajuste de P-J FIT é expandida para incluir a correspondência entre habilidades e suas demandas de trabalho (EDWARDS, 1991). Isso fica evidente também no estudo de Kristof-Brown, Zimmerman e Johnson (2005) ao constatar que a adaptação de P-J FIT se correlacionava fortemente com a intenção negativa de sair da organização.

\section{Person-Group Fit (P-G FIT)}

P-G FIT, ou alinhamento pessoa-grupo é definido como a compatibilidade entre indivíduos e seus grupos de trabalho (KRISTOF-BROWN, 1996). Ocorre de forma suplementar quando uma pessoa possui similaridade em valores, características psicológicas e comportamentais com os demais indivíduos do ambiente. Alternativamente, o ajuste complementar começa com uma "fraqueza ou necessidade do ambiente, se compensada pela força do indivíduo, e vice-versa." (MUCHINSKY; MONAHAN, 1987, p. 271, tradução nossa).

Embora estes dois tipos de ajustes devam ser distintos, as percepções de ajuste suplementar e complementar são frequentemente altamente correlacionadas (KRISTOFBROWN, 2000). Através de processos de atração e seleção, interação social, influências normativas e processos de liderança, os membros do grupo podem ter percepções similares dos valores do grupo e adequarem-se à equipe para atender às demandas (DERUE; MORGENSON, 2007) resultando assim em percepções coletivas de ajuste em nível de grupo.

Equipes com melhor alinhamento preveem melhor desempenho. Em geral, acreditase que um forte senso de coesão melhora a comunicação entre os membros do grupo, o que, por sua vez, facilita sua participação em maior grau e aumenta a aceitação de seus objetivos, tarefas e papéis (SEONG et al., 2012). 
A teoria do P-G FIT foi testada também em outros contextos, por exemplo, no meio acadêmico Wurster, Kivlighan e Foley-Nicpon (2020) destacam que o senso de pertencimento nos grupos de aprimoramento acadêmico e a influência complexa destes processos a nível de grupo foram altamente relacionados a melhoria de desempenho acadêmico.

\section{Person-Supervisor Fit (P-S FIT)}

Por fim, o P-S FIT, alinhamento pessoa-supervisor infere que há uma melhor performance quando ocorre um alinhamento positivo entre a pessoa e seu supervisor. Teorias de troca entre membros e líderes implicam que os supervisores têm uma variedade diferente de relacionamentos com seus diferentes funcionários. Diferentes tipos de interações ocorrem porque existem diferentes trocas sociais de qualidade diferenciadas entre um supervisor e seus subordinados. Esses diferentes tipos de relacionamento levam o supervisor à formas de tratamentos desiguais. Funcionários com relacionamentos de baixa qualidade geralmente executam tarefas impopulares em que não interagem frequentemente com seus líderes. Mais liberdade, melhor atribuições de trabalho, e aumento de oportunidades para trabalhar com líderes são algumas das vantagens observadas quando ocorre este tipo de alinhamento (SCHOON, 2008).

Para Tak (2011) P-S FIT diz respeito à correspondência entre subordinados e supervisores e ocorre quando estes compartilham características em comum. Satisfação no trabalho, confiança na liderança, aumento do volume de negócios são resultados fomentados por este tipo de ajuste nas organizaçoes.

Pesquisas sobre a relação entre supervisor e subordinados estão centradas no domínio de troca entre colaboradores e seus líderes (KRISTOF-BROWN; ZIMMERMAN; JOHNSON, 2005). Dienesch e Liden (1986) propuseram que a troca entre estes é um construto multidimensional e sugeriram que afeto, lealdade e contribuição eram três dimensões que deveriam ser consideradas. Este apontamento é importante para ajudar a entender melhor estes relacionamentos. Em seguida, similaridade ou congruência com ênfase especial em similaridade de personalidade, congruências entre valores e metas deve ser considerado.

Pesquisas realizadas por Zhang et al. (2015) identificaram que P-S FIT contribui para que haja comprometimento e engajamento no trabalho, bem como reduz a intenção de sair da organização. Outro estudo realizado em organizações Coreanas por Jin e Hahm (2019) identificou que o alinhemanto das pessoas com o ambiente de trabalho contribuem para melhorar a comunicação organizacional e corrobora com a satisfação no trabalho, enfatizando a importância do desenvolvimento de habilidade de comunicação entre os trabalhadores, em especial entre supervisores e subordinados.

Estudo realizado por Chi et al. (2019) identificou que o desajuste P-J é altamente decisivo para que as pessoas decidam deixar a organização, no entanto, o P-S FIT é capaz de amortecer os resultados negativos do desajuste, interferindo na permanência destes indivíduos nas organizações.

\section{PROCEDIMENTOS METODOLÓGICOS}

Quanto à abordagem esta pesquisa caracteriza-se como quantitativa. Segundo Creswell (2007) é aquela em que o investigador possui o intuito de desenvolvimento de conhecimento. A abordagem quantitativa, de acordo com Mascarenhas (2012, p. 45), "baseiase na quantificação para coletar e, mais tarde, tratar os dados obtidos". Segundo o autor, é fundamental o uso de técnicas estatísticas para tornar o estudo mais imparcial.

Com relação ao objetivo, caracteriza-se como descritivo, uma vez que segundo Gil 
(2010) esse tipo de estudo pretende descrever características de determinada população ou fenômeno, ou ainda estabelecer relações entre as variáveis analisadas.

Este estudo utilizou como amostra os dados das 456 empresas inscritas, em 2017, no ranking das "Melhores Empresas para Trabalhar". Os dados foram coletados por meio do Programa de Estudos em Gestão de Pessoas (PROGEP) da Fundação Instituto de Administração (FIA) em parceria com VOCÊ S/A (LAUDO TÉCNICO..., 2018).

Sendo assim, a base de dados para fins desta pesquisa é de ordem secundária e composta por dois índices, a saber: O Índice de Qualidade do Ambiente de Trabalho (IQAT), formado por resultados relativos à percepção/opinião de 250.273 funcionários. O questionário respondido por estes possuía 70 indicadores que envolvem dados sobre vivências organizacionais. As variáveis foram operacionalizadas com escala Likert de 5 pontos. O Índice de Qualidade da Gestão de Pessoas (IQGP) que se refere aos processos de gestão de pessoas nas organizações, coletado por meio de informações fornecidas pela empresa em um formulário eletrônico e pela análise das descrições dessas práticas. Os dados estatísticos, na etapa quantitativa, foram tratados com os softwares SPSS ${ }^{\circledR}$ Statistics - Statistical Package for the Social Sciences, versão 18.

\subsection{HIPÓTESES NORTEADORAS DA PESQUISA}

Com base na ideia central, suportada pela base teórica deste estudo, pressupõe-se que: Práticas de Gestão das Relações Interpessoais tenha impacto efetivo no alinhamento entre pessoas e o ambiente de trabalho (P-E FIT), sendo essas capazes de fomentar Resultados de $\mathrm{RH}$, representado pelo Índice de Turnover de funcionários. O Quadro 1 apresenta as hipóteses norteadoras de pesquisa.

Quadro 1 - Hipóteses norteadoras da pesquisa

\begin{tabular}{|c|c|}
\hline \multicolumn{2}{|c|}{$\begin{array}{l}\mathrm{H}_{1} \text { - Práticas de Gestão das Relações Interpessoais impactam em menor Índice de Turnover de funcionários } \\
\text { nas organizações. }\end{array}$} \\
\hline $\begin{array}{l}\mathrm{H}_{2} \text { - Práticas de Gestão } \\
\text { das Relações } \\
\text { Interpessoais impactam } \\
\text { positivamente no } \\
\text { alinhamento Person- } \\
\text { Environment Fit (P-E } \\
\text { FIT). }\end{array}$ & $\begin{array}{l}\mathrm{H}_{2 a} \text { - Práticas de Gestão das Relações Interpessoais impactam positivamente o } \\
\text { Person-Organization Fit (P-O FIT). } \\
\mathrm{H}_{2 b} \text { - Práticas de Gestão das Relações Interpessoais impactam positivamente o } \\
\text { Person-Job Fit (P-J FIT). } \\
\mathrm{H}_{2 c}-\text { Práticas de Gestão das Relações Interpessoais impactam positivamente o } \\
\text { Person-Group Fit (P-G FIT). } \\
\mathrm{H}_{2 \mathrm{~d}} \text { - As práticas de Gestão das Relações Interpessoais impactam positivamente } \\
\text { o Person-Supervisor Fit (P-S FIT). }\end{array}$ \\
\hline $\begin{array}{l}\mathrm{H}_{3}-\mathrm{O} \text { Person- } \\
\text { Environment Fit (P-E FIT) } \\
\text { medeia a relação entre } \\
\text { as práticas de Gestão } \\
\text { das Relações } \\
\text { Interpessoais e os } \\
\text { índices de Turnover. }\end{array}$ & $\begin{array}{l}\text { H3a - O Person-Organization Fit (P-O FIT) medeia a relação entre as práticas de } \\
\text { Gestão das Relações Interpessoais e os índices de Turnover. } \\
\text { H}_{3 b} \text { - O Person-Job Fit (P-J FIT) medeia a relação entre as práticas de Gestão das } \\
\text { Relações Interpessoais e os índices de Turnover. } \\
\text { H3c }_{3} \text { O Person-Group Fit (P-G FIT) medeia a relação entre as práticas de Gestão } \\
\text { das Relações Interpessoais e os índices de Turnover. } \\
\text { H3d - O Person-Supervisor Fit (P-S FIT) medeia a relação entre as práticas de } \\
\text { Gestão das Relações Interpessoais e os índices de Turnover. }\end{array}$ \\
\hline
\end{tabular}

Fonte: autoras.

\section{ANÁLISE DOS DADOS}

\subsection{ANÁLISE FATORIAL EXPLORATÓRIA}

Primeiramente, procedeu-se a análise fatorial como um método que analisa a frequência e dispersão dos dados coletados referente ao índice de P-E FIT. De acordo com Hair et al. (2005), no modelo de análise fatorial, cada uma das variáveis pode ser definida como uma combinação linear dos fatores comuns que irão explicar a parcela da variância de cada variável, mais um desvio 
que resume a parcela da variância total não explicada por estes fatores. A parcela explicada pelos fatores comuns recebe o nome de comunalidade e a parcela não explicada é chamada de especificidade.

Para definição dos fatores, procedeu-se a análise de comunalidade. As comunalidades podem variar de 0 a 1 , sendo que valores próximos de 0 indicam que os fatores comuns não explicam a variância e valores próximos de 1 indicam que todas as variâncias são explicadas pelos fatores comuns. Segundo Hair et al. (2005), 0,60 seria o mínimo para atestar comunalidade das variáveis, sendo desejável para a maioria delas. Das 70 variáveis, 27 apresentaram comunalidade menor que 0,60 e foram excluídas da amostra.

Em seguida, com as 43 variáveis, buscou-se identificar o número ideal de fatores. Para tanto a Tabela 1, exposta a seguir, exibe os primeiros 4 fatores utilizados, sendo que na análise de autovalores considerou-se os que fatores que indicam raízes latentes ou autovalores maiores que 1 e variância cumulativa representando $65,658 \%$. Os primeiros 4 fatores foram aceitos e confirmados na análise de autovalores pois estão de acordo com os parâmetros recomendados pela literatura (HAIR et al., 2005).

Tabela 1 - Extração autovalores das variáveis de P-E FIT

\begin{tabular}{|c|c|c|c|c|c|c|}
\hline \multirow{2}{*}{ Fatores } & \multicolumn{3}{|c|}{$\begin{array}{l}\text { Somas de extração de carregamentos ao } \\
\text { quadrado }\end{array}$} & \multicolumn{3}{|c|}{$\begin{array}{c}\text { Somas de rotação de carregamentos ao } \\
\text { quadrado }\end{array}$} \\
\hline & Total & $\begin{array}{c}\text { \% de } \\
\text { variância }\end{array}$ & $\%$ cumulativa & Total & $\begin{array}{c}\text { \% de } \\
\text { variância }\end{array}$ & $\%$ cumulativa \\
\hline 1 & 23,064 & 53,638 & 53,638 & 9,807 & 22,808 & 22,808 \\
\hline 2 & 2,320 & 5,396 & 59,034 & 6,722 & 15,633 & 38,441 \\
\hline 3 & 1,743 & 4,055 & 63,088 & 6,645 & 15,454 & 53,896 \\
\hline 4 & 1,105 & 2,570 & 65,658 & 5,058 & 11,762 & 65,658 \\
\hline
\end{tabular}

Fonte: Extraído do software SPSS e adaptado pelas autoras.

Neste sentido, 4 fatores foram considerados. Para certificar este contexto fez-se uso do teste de Kaiser-Meyer-Olklin (KMO) que serve também como critério para identificar se um modelo de análise fatorial está sendo utilizado é adequadamente ajustado aos dados, varia entre 0 a 1. Quanto mais perto de 1 , mais consistente o resultado. Field (2009) sugere a seguinte escala para interpretar o valor da estatística KMO: entre 0,90 e 1 excelente; entre 0,80 e 0,89 bom; entre 0,70 e 0,79 mediano; entre 0,60 e 0,69 medíocre; entre 0,50 e 0,59 ruim e entre 0 e 0,49 inadequado. Pallant (2007) sugere 0,6 como um limite razoável e Hair et al. (2005) sugerem 0,50 como patamar aceitável. Por fim, para complementar a análise a estatística Bartelett Test of Spherecity (BTS) deve ser estatisticamente significante $(p<0,05)$.

A Tabela 2 apresenta os resultados contextualizados.

Tabela 2 - Resultados do teste de KMO e BARTLETT

\begin{tabular}{|c|c|c|}
\hline \multicolumn{3}{|c|}{ Teste de KMO e Bartlett } \\
\hline \multicolumn{2}{|c|}{ Medida Kaiser-Meyer-Olkin de adequação de amostragem } & ,988 \\
\hline & Aprox. Qui-quadrado & 7320055,990 \\
\hline \multirow[t]{2}{*}{ Teste de esfericidade de Bartlett } & $\mathrm{Gl}$ & 903 \\
\hline & Sig. & ,000 \\
\hline
\end{tabular}

Fonte: Extraído do software SPSS e adaptado pelas autoras.

Como medida de adequação o teste de $\mathrm{KMO}=, 988$; esfericidade de Bartlett $\mathrm{p}<0,000$ atesta a validade para prosseguir com a análise fatorial. Em Seguida, procedeu-se a rotação dos dados para identificar a estrutura latente de relações, utilizando como método de extração a análise dos componentes principais (HAIR et al., 2005; DANCEY; REIDY, 2008; FIELD, 2009), pelo método Varimax com Normalização de Kaiser (HAIR et al., 2005).

Após identificação dos fatores, procedeu-se a análise de alfa de Cronbach, como um estimador de confiabilidade. Não há um valor mínimo definido para o coeficiente alfa de Cronbach ser aceito como adequado, mas a literatura recomenda o valor de 0,70 como mínimo aceitável 
(HORA; MONTEIRO; ARICA, 2010). Estando todos os fatores bem próximos a 0,9 não houve necessidade de eliminação de nenhum fator, sendo assim, procedeu-se à nomeação, de forma que refletisse as variáveis pertencentes, conforme Tabela 3.

Tabela 3 - Denominação dos fatores de Person-Environment FIT

Fator Indicadores por fator

v19 - Minha equipe de trabalho considera meu chefe um líder de respeito e credibilidade.

v41 - Tenho confiança naquilo que meu chefe diz.

v78 - Sou sempre bem atendido quando peço orientações ao meu chefe.

v24 - Meu chefe ajuda a decidir o que devo fazer para aprender mais.

v64 - Meu chefe ouve e respeita a opinião da sua equipe.

v51 - Minha equipe de trabalho tem um bom relacionamento com meu chefe.

v57 - Meu chefe conhece profundamente sua área de atuação.

1

v30 - Meu chefe sempre deixa claro o que espera do meu trabalho.

v46 - Meu chefe é coerente e usa o mesmo peso e a mesma medida nas suas decisões.

v61 - As solicitações e orientações de minha chefia facilitam a realização do meu trabalho.

v75 - As avaliações de desempenho recebidas do meu chefe contribuem para o meu

desenvolvimento.

v82 - Os chefes sabem demonstrar como podemos contribuir com os objetivos da empresa.

v43 - Nesta empresa os chefes agem de acordo com o que dizem.

v25 - Sou estimulado a contribuir para melhorar a forma como é feito o meu trabalho.

v20 - Recebo todas as informações que preciso para fazer bem o meu trabalho.

v62 - A quantia que recebo como remuneração variável ou participação nos lucros é justa.

v52 - A empresa utiliza critérios justos para promoção e crescimento na carreira.

v73 - Considero justo o salário pago por esta empresa aos seus funcionários.

v47 - Os treinamentos oferecidos pela empresa atendem às necessidades do meu trabalho.

v44 - Considero que meu trabalho é reconhecido e valorizado pela empresa.

v63 - Esta empresa oferece suporte se eu me sentir injustiçado no trabalho.

2 v48 - Considero que esta empresa atende de forma equilibrada às necessidades dos...

v26 - Sei o que devo fazer para crescer profissionalmente nesta empresa.

v81 - Esta empresa me estimula a conhecer o trabalho realizado pelos meus colegas.

v29 - Acredito que trabalhando nesta empresa terei oportunidade de fazer carreira e crescer.

v66 - Os processos, procedimentos e rotinas de trabalho desta empresa são organizadas.

v45 - Os métodos para realizar o trabalho nesta organização são frequentemente disc. e ver.

v42 - Tenho orgulho de dizer a parentes e amigos que trabalho nesta empresa.

v59 - Esta empresa tem um grande significado pessoal para mim.

v67- Tenho confiança na empresa em que trabalho.

V18 - Eu recomendaria aos meus parentes e amigos esta empresa como um excelente lugar...

v34 - Considero que trabalhar nesta empresa vem tornando a minha vida melhor.

3 v70 - Concordo com os objetivos da empresa em que trabalho.

v69 - Meus valores pessoais são muito similares aos valores defendidos pela minha empresa.

v77 - A sensação mais frequente que sinto ao deixar o trabalho é de realização profissional.

v86 - O trabalho que realizo nesta empresa apresenta desafios que estimulam o meu

desenvolvimento.

v28 - Na minha equipe, as pessoas estão sempre dispostas a ajudar umas às outras.

v83 - Na minha equipe, a gente pode confiar nos colegas de trabalho.

v33 - Sinto que minha equipe trabalha como um verdadeiro time.

4 v56 - Meus colegas estão sempre dispostos a dividir comigo o que sabem.

v71 - As pessoas que trabalham na minha equipe estão procurando melhorar aquilo que fazem.

v53 - Nesta empresa, posso confiar nos colegas de outras áreas.

v54 - O ambiente de trabalho da empresa facilita o relacionamento entre os funcionários.

Fonte: Extraído do software SPSS e adaptado pelas autoras.

Os fatores nominados (terceira coluna), inclusive, confirmam com as dimensões que a literatura atribui ao construto P-E FIT (KRISTOF-BROWN; ZIMMERMAN; JOHNSON, 2005) e 
identificados também nos trabalhos Andela e Van Der Doef (2018). Para efeito de análises subsequentes, utilizou-se a média conjunta das variáveis que pertencem a cada dimensão de P-E FIT, sendo eles: P-O FIT, P-J FIT, P-G FIT e P-S FIT.

\subsection{ANÁLISE DE REGRESSÃO}

As práticas de Gestão das Relações interpessoais foram coletadas nas 456 empresas da amostra de pesquisa e integraram o cálculo. Para esta variável procedeu-se a tabulação utilizando-se números absolutos devido à complexidade das práticas das Relações Interpessoais. Para cada uma das empresas foi atribuído um valor, ou seja, atribui-se um ponto para cada prática declarada e quando não havia nenhuma prática foi utilizado o indicador 0 . Os valores foram tabulados cumulativamente permitindo gerar uma pontuação de 0 a 20 pontos para cada empresa, conforme a declaração de existência das mesmas.

Como o Turnover representa a rotatividade de pessoas em uma organização foi calculado o número percentual deste índice com relação à sua totalidade de funcionários. Operacionalizou-se o cálculo por empresa utilizando-se o número total de demissões no ano de 2017 (variável 156 da base de dados IQGP) acrescido do número de admissões no ano de 2017 (variável 157 da base de dados IQGP) dividido por dois. O resultado foi dividido pelo número total de empregados (variável 30 da base de dados IQGP) e multiplicado por 100.

A Tabela 4 apresenta os resultados dos testes das hipóteses $\left(\mathrm{H}_{1}\right.$ e $\left.\mathrm{H}_{2}\right)$. No modelo 1 a variável dependente (V.D. Turnover) é expressa em função da variável independente (conjunto de práticas de Gestão das relações interpessoais), enquanto nos modelos 2, 3, 4 e 5 as variáveis Mediadoras (MED1; MED2; MED3; MED4) são expressas em função da variável independente (conjunto de práticas de Gestão das Relações Interpessoais).

Tabela 4 - Resultado da análise de regressão

\begin{tabular}{|c|c|c|c|c|c|}
\hline \multicolumn{2}{|l|}{ Passo 1} & \multicolumn{4}{|c|}{ Passo 2} \\
\hline & V.D. & (MED1) & (MED2) & (MED3) & (MED4) \\
\hline & Índice de Turnover & P-S FIT & P-J FIT & P-O FIT & P-G FIT \\
\hline (V.I.) & Modelo 1 & Modelo 2 & Modelo 3 & Modelo 4 & Modelo 5 \\
\hline Práticas de Gestão das Relações & $-1,296 * *$ & $0,011^{*}$ & $0,052 * * *$ & $0,032 * * *$ & $0,031 * * *$ \\
\hline & & $30,283^{* *}$ & & & \\
\hline & $30,283 * * *$ & $*$ & $-0,241 * * *$ & $-0,194 * * *$ & $-0,108 * * *$ \\
\hline Constante (unstandardized) & $(2,549)$ & $(0,030)$ & $(0,039)$ & $(0,042)$ & $(0,036)$ \\
\hline $\mathrm{F}$ & 5,678 & 2,964 & 38,234 & 13,071 & 16,831 \\
\hline$p$-value & 0,018 & 0,086 & 0,000 & 0,000 & 0,000 \\
\hline$R^{2}$ & 0,016 & 0,008 & 0,096 & 0,035 & 0,045 \\
\hline $\mathrm{R}^{2}$ ajustado & 0,013 & 0,005 & 0,094 & 0,032 & 0,042 \\
\hline
\end{tabular}

$* \mathrm{p}<0,1 * * \mathrm{p}<0,05 * * * \mathrm{p}<0,01$

Fonte: Extraído do software SPSS e adaptado pelas autoras.

O teste de regressão do Modelo 1 indicou que o conjunto das práticas de Gestão das Relações Interpessoais tem influência negativa e significativa $\left(-1,296^{* *}\right)$ sobre os índices de Turnover, suportando a Hipótese $\mathrm{H}_{1}$.

Percebeu-se que o conjunto de práticas de Gestão das relações interpessoais influencia os índices de Turnover, de modo que a utilização de sistemas trabalho de alta performance (HPWS) está associado com menor Turnover. Este resultado relaciona-se aos resultados apresentados por Tibola (2012) e de Appio e Fernandes (2015) que identificaram que práticas de gestão de pessoas exerciam papel preditivo na rotatividade de funcionários. Gestão das Práticas de Relações Interpessoais já haviam sido entendidas como uma HPWS chave nos estudos de Huselid (1995) e Posthuma et al. (2013). Outro estudo que corrobora com este foi 
realizado em 273 organizações indianas Bhattacharya, Kunte e Sharma (2018) identificaram que o não alinhamento das pessoas em seus ambientes de trabalho contribuem para a intenção de se afastar da organização, ou seja, poderá levar a rotatividade.

A qualidade dessas relações e o ambiente de trabalho como influência na decisão dos funcionários em permanecerem ou deixarem uma organização também foram corroborados nos trabalhos de Chuang e Liao (2010), com 133 organizações de Taiwan. Kim e Wright (2011) identificaram fatores contingentes na escolha voluntária de sistemas de trabalho e concluíram que as relações pessoais em conexão com HPWS refletem em alto nível de comprometimento.

A rotatividade voluntária, um dos indicadores que compõem o índice de Turnover, também foi investigada por Selden e Sowa (2015) que buscaram compreender o impacto das HPWS em 162 organizações não governamentais americanas e destacam que melhores níveis de relações com seus funcionários manifestaram menor nível de rotatividade voluntária, tendo a compensação com um fator preditivo deste contexto.

Nos modelos que correspondem a segunda parte, avaliou-se a Hipótese $\mathrm{H}_{2}$, nesta, infere-se que o conjunto de práticas de Gestão das Relações Interpessoais afeta positivamente o P-E FIT, suportando assim as hipóteses $\mathrm{H}_{2 a}, \mathrm{H}_{2 b}, \mathrm{H}_{2 c}$, entretanto, a $\mathrm{H}_{2 \mathrm{~d}}$ não foi suportada.

O modelo 2 refere-se ao pressuposto de que as práticas de Gestão das Relações Interpessoais impactam positivamente o P-S FIT, e esta relação não possui significância estatística $(p>0,05)$ rejeitando a Hipótese $\mathrm{H}_{2 d}$.

$\mathrm{O}$ modelo 3 suporta a hipótese $\mathrm{H}_{2 \mathrm{~b}}$, inferindo que as práticas de Gestão das Relações Interpessoais impactam positivamente o P-J FIT, apresentando coeficiente 0,052 e nível de significância de $p<0,01$, infere-se que o relacionamento interpessoal contribui com 0 alinhamento entre funcionários e seu próprio trabalho, uma vez que permite trocas de cunho teórico e técnico. O compartilhamento de informações dentro das organizações permite maior clareza na execução de tarefas, bem como, contribui para um clima de segurança.

$\mathrm{O}$ modelo 4 suporta a hipótese $\mathrm{H}_{2 \mathrm{a}}$. Infere-se que as práticas de Gestão das Relações Interpessoais impactam positivamente o P-O FIT, apresentando coeficiente 0,032 e nível de significância de $p<0,01$. Prediz-se que o relacionamento interpessoal esteja relacionado ao alinhamento entre funcionários e organizações, uma vez que quando se compartilha valores semelhantes há identificação entre estes agentes. Sentimentos de pertencimento e orgulho contribuem para resultados organizacionais mais satisfatórios.

Por fim, o modelo 5 suporta a hipótese $\mathrm{H}_{2 c}$, inferindo-se que o conjunto de práticas de Gestão das Relações Interpessoais afeta positivamente o P-G FIT, apresentando coeficiente de 0,031 e nível de significância de $p<0,01$. Este resultado pode ser fruto do bom relacionamento entre as pessoas com seus grupos de trabalho e contribuir para o maior alinhamento e confiança mútua. O Quadro 2, apresenta resposta as hipóteses $\mathrm{H}_{1} \mathrm{e}_{2}$.

Quadro 2 - Resposta as hipóteses $\mathrm{H}_{1}$ e $\mathrm{H}_{2}$

\begin{tabular}{|c|c|c|}
\hline \multicolumn{2}{|c|}{$\begin{array}{l}\mathrm{H}_{1} \text { - Práticas de Gestão das Relações Interpessoais impactam em menor Índice de Turnover de } \\
\text { funcionários nas organizações. }\end{array}$} & Confirmada \\
\hline \multirow{4}{*}{$\begin{array}{l}\mathrm{H}_{2} \text { - Práticas de Gestão das } \\
\text { Relações Interpessoais } \\
\text { impactam positivamente no } \\
\text { alinhamento Person- } \\
\text { Environment Fit (P-E FIT). }\end{array}$} & $\begin{array}{l}\mathrm{H}_{2 a} \text { - Práticas de Gestão das Relações Interpessoais impactam } \\
\text { positivamente o Person-Organization Fit (P-O FIT). }\end{array}$ & Confirmada \\
\hline & $\begin{array}{l}\mathrm{H}_{2 b} \text { - Práticas de Gestão das Relações Interpessoais impactam } \\
\text { positivamente o Person-Job Fit (P-J FIT). }\end{array}$ & Confirmada \\
\hline & $\begin{array}{l}\mathrm{H}_{2 c} \text { - Práticas de Gestão das Relações Interpessoais impactam } \\
\text { positivamente o Person-Group Fit (P-G FIT). }\end{array}$ & Confirmada \\
\hline & $\begin{array}{l}\mathrm{H}_{2 \mathrm{~d}} \text { - As práticas de Gestão das Relações Interpessoais } \\
\text { impactam positivamente o Person-Supervisor Fit (P-S FIT). }\end{array}$ & Refutada \\
\hline
\end{tabular}

Fonte: resultados da pesquisa. 
Como contextualizado há evidências que sustentam as hipóteses $\mathrm{H}_{1}$ e $\mathrm{H}_{2}\left(\mathrm{H}_{2 \mathrm{a}}, \mathrm{H}_{2 b} \mathrm{e}\right.$ $\mathrm{H}_{2 c}$ ). No entanto, o modelo apresentado tem baixo poder de explicação. Esta realidade pode estar atrelada aos limitantes desta pesquisa, que se utiliza da amostra de maneira conjunta, desconsiderando tamanho, porte, área de atuação e complexidade das organizações pesquisadas e pode influenciar pontualmente em alguns resultados, além do mais, pode também ser influenciado pela questão de estar-se utilizando de apenas um conjunto de prática de singular, quando o resultado pode estar associado à sinergia com demais práticas.

\subsection{ANÁLISE DE MEDIAÇÃO}

Para seguir a análise do efeito de mediação (Hipótese $\mathrm{H}_{3}$ ), recomenda-se a utilização de Teste de Sobel, Teste de Arolan e Teste de Godman. Os resultados dos mesmos estão apresentados na Tabela 5.

Tabela 5 - Efeito mediador de Person-Environment Fit

\begin{tabular}{|c|c|c|c|c|c|}
\hline & Turnover & Turnover & Turnover & Turnover & Turnover \\
\hline Variáveis & Modelo 1 & Modelo 2 & Modelo 3 & Modelo 4 & Modelo 5 \\
\hline \multirow{2}{*}{ Práticas de Gestão das Relações Interpessoais } & $-1,296 * * *$ & $-1,450 * * *$ & $-1,599 * * *$ & $-1,040 *$ & $-1,269 * *$ \\
\hline & $(0,544)$ & $(0,540)$ & $(0,571)$ & $(0,550)$ & $(0,557)$ \\
\hline (MED1) & - & $14,096 * * *$ & - & - & - \\
\hline P-S FIT & - & $(4,472)$ & - & - & - \\
\hline (MED2) & - & - & $5,822 *$ & - & - \\
\hline P-J FIT & - & - & $(3,405)$ & - & - \\
\hline (MED3) & - & - & - & $-7,881 * *$ & - \\
\hline P-O FIT & - & - & - & $(3,174)$ & - \\
\hline (MED4) & - & - & - & - & $-0,877$ \\
\hline P-G FIT & - & - & - & - & $(3,767)$ \\
\hline Constante & $30,283 * * *$ & $30,982 * * *$ & $31,687 * * *$ & $28,757 * * *$ & $30,189 * * *$ \\
\hline (unstandardized) & $(2,549)$ & $(2,582)$ & $(2,672)$ & $(2,604)$ & $(2,585)$ \\
\hline $\mathrm{F}$ & 5,678 & 7,878 & 4,316 & 5,962 & 2,859 \\
\hline$p$-value & 0,018 & ,000 & 0,014 & 0,003 & 0,059 \\
\hline $\mathrm{R}^{2}$ & 0,016 & 0,042 & 0,024 & 0,032 & 0,016 \\
\hline $\mathrm{R}^{2}$ ajustado & 0,013 & 0,037 & 0,018 & 0,027 & 0,010 \\
\hline $\begin{array}{l}\text { Efeito Mediador } \\
\text { (V.I. -> MED -> V.D) }\end{array}$ & - & 0,155 & 0,301 & $-0,252$ & $-0,027$ \\
\hline Teste de Sobel & - & 0,166 & $1,655^{*}$ & $-2,036 * *$ & $-0,232$ \\
\hline Teste de Arolan & - & 0,159 & 1,637 & $-1,984 * *$ & $-0,223$ \\
\hline Teste de Goodman & - & 0,175 & $1,674^{*}$ & $-2,091 * *$ & $-0,243$ \\
\hline
\end{tabular}

$* p<0,1 * * p<0,05 * * * p<0,01$

Fonte: Extraído do software SPSS e adaptado pelas autoras.

De acordo com o exposto, observa-se, em primeiro lugar, que as variáveis P-S FIT (MED1), P-J FIT (MED2) e P-G FIT (MED4) não são mediadoras na relação entre o conjunto de práticas de gestão das Relações Interpessoais e Performance dos índices de Turnover, rejeitando as Hipóteses $\mathrm{H}_{3 \mathrm{~d}} \mathrm{H}_{3 \mathrm{c}}$ e $\mathrm{H}_{3 b}$. Esse resultado pode ser visualizado nos testes de Sobel, Arolan e Goodman que não foram significativos e indicam coeficientes menores do que 1,96 - a literatura indica que coeficiente deve ser superior a 1,96 para significância de $p<0,05$ (HAIR et al., 2005).

Cabe então dizer que o alinhamento P-E FIT (P-S FIT, P-J FIT e P-G FIT) não medeia a relação entre as práticas de Gestão das Relações Interpessoais e os índices de Turnover investigados neste estudo. Em outras palavras, embora haja uma relação positiva entre Práticas de Relacionamento Interpessoal e P-S FIT, P-J FIT e P-G FIT constata-se que a relação 
não é mediadora de índices de Turnover, sendo que o alinhamento que impacta em melhoria do índice de Turnover é proveniente de outas fontes.

No estudo realizado por Zhang et al. (2015) também se destaca relação direta entre o P-S FIT com a redução da intenção de sair da organização, pois nao houve mediação. Entretanto, no estudo de Yang, Pu e Guan (2019) os autores identificaram que o alinhamento P-S FIT é mediador na relação entre líderes organizacionais e Turnover.

A variável P-O FIT (MED3), entretanto, pode ser considerada mediadora, confirmando a hipótese $\mathrm{H}_{3 \mathrm{a}}$, pois atendeu aos testes de Sobel $\left(-2,036^{* *}\right)$, Aroian $\left(-1,984^{* *}\right)$ e Goodman ($\left.2,091^{* *}\right)$ que foram significativos e indicaram coeficientes dentro dos padrões propostos pela literatura $( \pm 1,96)$ com significância de $p<0,05$ (HAIR et al., 2005), de modo que o efeito da relação entre as Práticas de Relações Interpessoais e Turnover $(-1,296)$ foi amenizada na presença da variável mediadora P-O FIT $(-0,252)$, conforme orientado pela literatura (BARON; KENNY, 1986; VIEIRA, 2009), mesmo que o poder de explicação dos modelos é baixo, pois apresentaram resultados de representatividade frágeis.

Assim, entende-se que há alguma contribuição do alinhamento P-O FIT na relação entre Práticas das Relações Interpessoais sobre o Turnover. Esta conjuntura, parece elucidar a percepção de que a identificação entre os funcionários e a organização, dada por meio do compartilhamento de valores similares influencia na intenção dos funcionários em permanecer. Esse resultado convergente com os resultados de Ertas (2019) ao concluir que PO FIT é relevante para a retenção, pois a sua ausência aumenta a rotatividade.

Em seguida, destaca-se que o P-J FIT não contribui na relação entre Práticas das Relações Interpessoais sobre o Turnover, uma vez que, este alinhamento esteja relacionado diretamente com as atividades a serem executadas pelo indivíduo, o trabalho a ser realizado propriamente dito, tendo assim pouco efeito sobre relacionamentos e sua relação com a intenção de rotatividade.

Entende-se que os ajustes P-S FIT e P-G FIT P-J FIT não contribuem na relação entre Práticas das Relações Interpessoais sobre o Turnover, cabendo-se considerar que outras variáveis podem ser relevantes para estes alinhamentos. Ainda que o relacionamento interpessoal interfira diretamente na qualidade das relações com supervisores e com demais integrantes dos grupos de trabalho, ao que se pode perceber, essas associações se contextualizam de forma complexa e sofrem interferências de outros fatores. Não só o relacionamento estabelecido, mas questões contingenciais, como recompensa, nível de exigência, satisfação e sentimentos de pertencimento e confiança podem, por exemplo, influenciar esta realidade.

Mesmo não se verificando mediação para os fatores P-S FIT, P-J FIT e P-G FIT, ainda de acordo com a Tabela 5, o resultado da regressão linear demonstra uma ligação direta entre estes alinhamentos e o Turnover. A relação entre P-S FIT e Turnover apresentou coeficiente 1,450 com significância de $p<0,01$, da mesma forma, o ajuste P-J FIT -1,599 com significância p<0,01 e o alinhamento P-G FIT coeficiente de $-1,269$ e significância de $p<0,05$, o que compreende dizer que quanto maior estes alinhamentos, menor tende a ser a rotatividade dos funcionários da empresa.

O Quadro 3, apresenta resposta a Hipótese $\mathrm{H}_{3}$ e seus desmembramentos. Este resultado corrobora a outros estudos encontrados na literatura, por exemplo, Lyon e O'Brien (2006) investigaram o impacto de P-E FIT em satisfação no trabalho e intenção de rotatividade em funcionários afro-americanos. A análise correlacionou a resposta de 204 funcionários e concluiu que as percepções deste ajuste explicaram o nível de variação em satisfação de trabalho em $43,20 \%$ e a intenção de rotatividade em $20,20 \%$. A correlação entre satisfação de 
trabalho e intenção de saída da organização também se apresentou negativa o que compreende que é um preditor de retenção de pessoas.

\begin{tabular}{|c|c|c|}
\hline \multirow{4}{*}{$\begin{array}{l}\mathrm{H}_{3} \text { - O Person- } \\
\text { Environment Fit (P-E } \\
\text { FIT) medeia a relação } \\
\text { entre as práticas de } \\
\text { Gestão das Relações } \\
\text { Interpessoais e os } \\
\text { índices de Turnover. }\end{array}$} & $\begin{array}{l}\mathrm{H}_{3 a} \text { - O Person-Organization Fit (P-O FIT) medeia a relação entre as } \\
\text { práticas de Gestão das Relações Interpessoais e os índices de } \\
\text { Turnover. }\end{array}$ & Confirmada \\
\hline & $\begin{array}{l}\mathrm{H}_{3 b} \text { - O Person-Job Fit (P-J FIT) medeia a relação entre as práticas de } \\
\text { Gestão das Relações Interpessoais e os índices de Turnover. }\end{array}$ & Refutada \\
\hline & $\begin{array}{l}\mathrm{H}_{3 c} \text { - O Person-Group Fit (P-G FIT) medeia a relação entre as práticas } \\
\text { de Gestão das Relações Interpessoais e os índices de Turnover. }\end{array}$ & Refutada \\
\hline & $\begin{array}{l}\text { H3d - O Person-Supervisor Fit (P-S FIT) medeia a relação entre as } \\
\text { práticas de Gestão das Relações Interpessoais e os índices de } \\
\text { Turnover. }\end{array}$ & Refutada \\
\hline
\end{tabular}

Fonte: resultados da pesquisa.

O estudo empírico realizado por Memon et al. (2014) concluiu que o ajuste P-O FIT (em termos de valores e congruências de metas) fornece significativo apelo psicológico e por consequência envolvimento dos funcionários. Sendo que ao longo prazo, indivíduos com mais alto nível de envolvimento teriam menor probabilidade de deixar a organização voluntariamente. O trabalho de Memon et al. (2014) propõe que satisfação tem efeito mediador sobre intenção de rotatividade de funcionários.

McCulloch e Turban (2007) examinaram o valor incremental de uma medida de P-O FIT como uma ferramenta de seleção para prever o tempo de serviço e desempenho para agentes de call center, um trabalho historicamente de alta rotatividade. $\mathrm{O}$ ajuste do P-O FIT foi operacionalizado como a correlação entre as descrições dos gestores da cultura de trabalho com as preferências de trabalho dos participantes. Os autores concluíram que o P-O FIT acrescentou uma variação incremental significativa na previsão da retenção de funcionários, mesmo que não possa prever desempenho.

\section{CONSIDERAÇÕES FINAIS}

Estudos recentes tendem a estabelecer a articulação das políticas e práticas de gestão de $\mathrm{RH}$ com a estratégia de negócio, focalizando-se em mensurar resultados organizacionais a partir de agrupamentos ou combinação de práticas de GRH e a análise de seus impactos no desempenho das empresas.

As relações interpessoais consistem em processos de mutualidade, inerente ao convívio humano, e quando bem articuladas no ambiente organizacional permitem trocas de cunho técnico, teórico e compartilhamento de experiências que revertem em benefício à organização.

Os resultados encontrados neste estudo respondem à pergunta de pesquisa e corroboram com outros estudos expostos na análise, inferindo que a qualidade dos relacionamentos é um fator determinante para a retenção de pessoas. Políticas organizacionais que determinem práticas focadas a gerir este contexto devem contribuir para a decisão do funcionário em permanecer em determinada organização, cooperando assim para a preservação do capital intelectual organizacional e evitando gastos inerentes ao processo de Turnover, que vão além dos custos com desligamentos, mas implicam em custos de treinamento e qualificação destas pessoas. Entendendo-se que gerir relacionamentos temse consolidado como uma importante prática de HPWS, como já mencionado em um dos trabalhos sistemáticos mais relevantes publicados, para indicar, Posthuma et al. (2013).

Quando há identificação, dada por meio do compartilhamento de valores similares, o 
que pode ser entendido como alinhamento P-O FIT, há uma propensão já identificada em diversos estudos de que os funcionários queiram permanecer nestas organizações, contribuindo com a menor incidência de Turnover. Os demais ajustes P-E FIT (P-S FIT, P-J FIT e P-G FIT) não podem ser considerados mediadores entre a relação entre as práticas de Gestão das Relações Interpessoais e os índices de Turnover investigados neste estudo. Cabe, porém, interpor que se identificou um efeito direto destas variáveis com os índices de Turnover, sendo estas relações significativas, assim, entende-se que os alinhamentos do constructo P-E FIT interferem diretamente na rotatividade organizacional. Quanto maiores os níveis desse alinhamento mais propensos a permanecerem nestas organizações estarão os indivíduos.

Este estudo de caráter empírico contribui com a literatura inferindo conhecimentos adjacentes à publicação de outros autores. Quanto mais informações forem produzidas, mais elucidado será o caminho que permite às organizações reterem seus talentos. Na tentativa de desvendar a referida "black box" pode-se assegurar que as práticas de Relações Interpessoais têm impacto positivo sobre o P-E FIT. Esta informação e as demais conclusões pertinentes nesta pesquisa podem contribuir para a realização de outros estudos empíricos.

Como limitações desse estudo pode-se destacar que as conclusões se restringem apenas à amostra selecionada, a qual não seleciona as empresas por porte, estrutura e complexidade, inferindo resultados gerais. É também um fator limitante é o corte transversal, o que não permite verificar se estes resultados são coerentes ao longo do tempo. Destaca-se ainda o perfil dos respondentes, sendo um ranking de empresas, os respondentes podem tender a passar uma imagem positiva da organização e neste mesmo sentido, em caso contrário, negligenciar suas respostas como forma de demonstrar seus descontentamentos e percepções individuais, distorcendo realidades.

Assim, o presente estudo deve ser interpretado dentro do contexto de suas limitações. O baixo poder explicativo dos modelos também sugere a interferência de outras variáveis nas relações investigadas. As práticas de Relações Interpessoais foram analisadas em isolado, no entanto, sua efetividade pode correlacionar-se à sinergia de outras práticas.

Sugerem-se como possíveis pesquisas futuras estudos sobre este tema, englobando as "Melhores Empresas para Trabalhar", bem como, a reincidência desta pesquisa nos anos subsequentes para verificar se os resultados se confirmam ao longo do tempo. Da mesma forma, pode-se determinar amostra considerando classificação das organizações por ramo de atuação e/ou porte organizacional em busca de maior robustez de resultados. Pesquisas de mesmo perfil, utilizando-se de outras variáveis de práticas organizacionais também são indicadas, o que podem contribuir para elucidar os resultados aqui corroborados.

\section{REFERÊNCIAS}

ANDELA, M.; VAN DER DOEF, M. A Comprehensive assessment of the person-environment fit dimensions and their relationships with work-related outcomes. Journal of Career Development, Columbia, v. 46, p. 567-582, 2018. DOI: https://doi.org/10.1177/0894845318789512.

APPIO, J.; FERNANDES, B. H. R. Práticas de gestão de pessoas, alinhamento pessoa-ambiente de trabalho e índices de turnover: um estudo nas "Melhores Empresas Para Você Trabalhar" no Brasil. BASE - Revista de Administração e Contabilidade da UNISINOS, São Leopoldo, v. 12, n. 2, p. 82-95, 2015. DOI: https://doi.org/10.4013/base.2015.122.01.

ARTHUR, J. B. Effects of human resource systems on manufacturing performance and

RGO - Revista Gestão Organizacional, Chapecó, v. 13, n. 2, p. 162-187, maio/ago. 2020. 
turnover. Academy of Management Journal, Westchester, v. 376, p. 670-687, 1994. DOI: https://doi.org/10.2307/256705.

BARON, R. M.; KENNY, D. A. The moderator-mediator variable distinction in social psychological research: conceptual, strategic, and statistical consideration. Journal of Personality and Social Psychology, Washington, v. 51, n. 6, p. 1173-1182, 1986. DOI: https://doi.org/10.1037/0022-3514.51.6.1173.

BARRETO, J. F. G. S. 0 desempenho como preditor das intenções de saída: A idade faz a diferença? 2014. Dissertação (Mestrado em Psicologia Social) - Instituto Universitário de Ciências Psicológicas, Sociais e da Vida, Lisboa, Portugal, 2014.

BECKER, B. E.; GERHART, B. The impact of human resource management on organizational performance: progress and prospects. Academy of Management Journal, Westchester, v. 39, n. 4, 779-801, 1996. DOI: https://doi.org/10.2307/256712.

BECKER, B. E.; HUSELID, M. A. High performance work systems and firm performance: a synthesis of research and managerial implications. Research in Personnel and Human Resources Management, Bingley, v. 16, p. 53-101, 1998.

BHATTACHARYA, S.; KUNTE, M.; SHARMA, P. Cultural factors affecting early turnover intention moderated by person-job fit and person-supervisor fit. International Journal of Indian Culture and Business Management, Genéva, v. 17, n. 3, p. 338-358, 2018. DOI: https://doi.org/10.1504/IJICBM.2018.10015361.

BIANCHI, E. M. P. G.; ALBUQUERQUE, L. G. de. Alinhamento entre estratégias de negócio e gestão de pessoas: um caso da indústria química brasileira. RACE - Revista de Administração, Contabilidade e Economia da FUNDACE, São Paulo, v. 2, n. 1, 2011. DOI: http://dx.doi.org/10.13059/racef.v2i1.29.

BRANDÃO, H. P. Mapeamento de competências: métodos, técnicas e aplicações em gestão de pessoas. São Paulo: Atlas, 2012.

CARDOSO, L. Práticas de gestão de recursos humanos e desempenho organizacional. 2012. Tese (Mestrado em Psicologia Social) - Instituto Universitário Ciências Psicológicas, Sociais e da Vida, Lisboa, Portugal. 2012.

CHATMAN, J. A. Improving interactional organizational research: A model of personorganization fit. Academy of Management Review, New York, v. 14, p. 333-349, 1989. DOI: https://doi.org/10.2307/258171.

$\mathrm{CHEW}, \mathrm{J}$. C. L. The influence of human resource management practices on the retention of core employees of Astralian Organizations: an empirical study. 2004. Thesis (Doctor of Philosophy) - Murdoch University, Australia, 2004.

CHI, N. W.; FANG, L. C.; SHEN, C. T.; FAN, H. L. Detrimental effects of newcomer person-job misfit on actual turnover and performance: the buffering role of multidimensional personenvironment fit. Applied Psychology, Berlin, v. 1, p. 1-17, 2019. DOI:

https://doi.org/10.1111/apps.12225. 
CHIAPPELI, F.; KUTSCHMAN, M. M. Person-environment (P-E) fit in dental practice. Dent Hypotheses, Munbai, v. 7, p. 1-3, 2016. DOI: https://doi.org/10.4103/2155-8213.177372.

CHOI, M.; YOO, T. The effects of person-organization, person-job, and person-supervisor fit on organizational commitment, job satisfaction, and turnover intention: The focus on interaction effects among three types of fit. Korean Journal of Industrial and Organizational Psychology, Republic of Korea, v. 18, p. 139-162, 2005.

CHUANG, C; LIAO, H. Strategic human resource management in service context: Taking care of business by taking care of employees and customers. Personnel Psychology, Limerick, v. 63, p. 153-196, 2010. DOI: https://doi.org/10.1111/j.1744-6570.2009.01165.x.

COSTA, W. S. da. Humanização, relacionamento interpessoal e ótica. Caderno de pesquisas em Administração, São Paulo, v. 11, n. 1, p. 17-21, jan./mar., 2004.

CRESWELL, J. W. Projeto de pesquisa: métodos qualitativo, quantitativo e misto. 2. ed. Porto Alegre: Artmed, 2007.

DANCEY, C. P.; REIDY, J. Estatística sem Matemática para Psicologia: Usando SPSS para Windows. 3. ed. Porto Alegre: Artmed, 2008.

DELERY, J. E.; DOTY, H. Modes of Theorizing in Strategic Human Resource Management: tests of universalistic, contingency and configuracional performance predictions. Academy of Management Journal, Westchester, v. 39, n.4, p.802-835, 1996. DOI:

https://doi.org/doi.org/10.5465/256713.

DERUE, D. S.; MORGESON, F. P. Stability and change in person-team and person-role fit over time: The effects of growth satisfaction, performance, and general self-efficacy. Journal of Applied Psychology, Bethesda, v. 92, n. 5, p. 1242-1253, 2007. DOI:

https://doi.org/10.1037/0021-9010.92.5.1242.

DIENESCH, R. M.; LIDEN, R. C. Leader-member exchange model of leadership: A critique and further development. Academy of Management Review, New York, v. 11, p. 3, p. 618- 634, 1986. DOI: https://doi.org/10.2307/258314.

DO, H. High-Performance work systems and organisational performance: evidence from the Vietnamese Service Sector. 2015. Theses (Doctor of Philosophy) - Aston University, Birmingham, Inglaterra, 2015.

DUTRA, J. S. Competências. Conceitos e instrumentos para a gestão de pessoas na empresa moderna. São Paulo: Atlas, 2010.

EDWARDS, J. R. Person-job fit: A conceptual integration, literature review, and methodological critique. In C. L. Cooper \& I. T. Robertson (Eds.), International review of industrial and organizational psychology, v. 6, p. 283-357. New York: Wiley, 1991.

EDWARDS, J. R. 4 Person-environment fit in organizations: an assessment of theoretical progress. The Academy of Management Annals, New York, v. 2, n. 1, p. 167-230, 2008. DOI: https://doi.org/10.1080/19416520802211503. 
EDWARDS, J. R. An examination of competing versions of the person-environment: Fit approach to stress. Academy of Management Journal, Westchester, v. 39, n. 2, p. 292-339, 1996. DOI: https://doi.org/10.2307/256782.

ERTAS, N. Turnover intentions of volunteer resource managers: the roles of work motivations, person-organization fit, and emotional labor. International Journal of Public Administration, Florida, v. 42, n. 9, p. 741-752, 2019.

DOI: https://doi.org/10.1080/01900692.2018.1506935.

FERNANDES, H. N.; THOFEHRN, M. B.; PORTO, A. R.; AMESTOY, S. C. JACONDINO, M. B.; SOARES, M. R. Relacionamento interpessoal no trabalho da equipe multiprofissional de uma unidade de saúde da família. Revista pesquisa e cuidados fundamentais (Online), Pelotas, v. 7, n. 1, p. 1915-1926, jan./mar. 2015.

FIELD, A. Descobrindo a estatística usando o SPSS. 2.ed. São Paulo: Artmed, 2009.

FRANCISCO, J. D. da Silva. As relações entre satisfação no trabalho, comprometimento organizacional afetivo e intenção de rotatividade: um estudo em uma mineradora de diamantes na angola. 2015. Dissertação (Mestrado em Administração), Faculdade de Administração e Economia da Universidade Metodista de São Paulo, São Bernardo do Campo, SP, 2013.

GIDDENS, A. Social Theory and Modern Sociology. Cambridge: Polity Press; 1987.

GIL, A. C. Como elaborar projetos de pesquisa. 5. ed. São Paulo: Atlas, 2010.

GONÇALVES, G. F.; MOLLICA, A. M. V. Turnover no mercado de trabalho mundial. Caderno Científico FAGOC de Graduação e Pós-Graduação, Ubá, v. 1, n. 1, p. 67-76, 2016.

GUEST, D. Human resource management and performance: still searching for some answers. Human Resource Management Journal, Yorkshire, v. 21, n. 1, p. 3-13, 2011. DOI: https://doi.org/10.1111/j.1748-8583.2010.00164.x.

HAIR JR., J. F.; ANDERSON, R. E.; TATHAM, R. L.; BLACK, W. C. Análise multivariada de dados. 5. ed. Porto Alegre: Bookman, 2005.

HORA, H. R. M.; MONTEIRO, G. T. R.; ARICA, J. Confiabilidade em questionários para qualidade: um estudo com o coeficiente Alfa de Cronbach. Produto \& Produção, Porto Alegre, v. 11, n. 2, p. 85-103, 2010. DOI: https://doi.org/10.22456/1983-8026.9321.

HUSELID, M.A. The impact of human resource management practices on turnover, productivity, and corporate financial performance. Academy of Management Journal, Westchester, v. 38, n. 3, p. 635-672, 1995.

JIN, X.; HAHM, S. W. The way to improve employees' job satisfaction in Korean social enterprises: the moderating effects of person-organization fit, person-job fit, and personsupervisor fit. International Journal of Financial Research, Raipur, v. 10, n. 5, 2019. DOI: https://doi.org/10.5430/ijfr.v10n5p347.

KAUFMAN, B. E. S. SHRM Theory in the Post-Huselid Era: Why It Is Fundamentally 
Misspecified. Industrial Relations. A Journal of Economy and Society, Los Angeles, v. 49, n. 2, p. 286-313, 2010.

KIM, S.; WRIGHT, P. M. Putting strategic human resource management in context: A contextualized model of high commitment work systems and its implications in China.

Management \& Organization Review, Cambridge, v. 7, p. 153-174, 2011. DOI: https://doi.org/10.1111/j.1740-8784.2010.00185.x.

KRISTOF-BROWN, A. L. Perceived applicant fit: Distinguishing between recruiters' perceptions of person-job fit and person-organization fit. Personnel Psychology, Limerick, v. 53, p. 643-671, 2000. DOI: https://doi.org/10.1111/j.1744-6570.2000.tb00217.x.

KRISTOF-BROWN, A. L. Person-organization Fit: An integrative review of its conceptualizations, measurement, and implications. Personnel Psychology, Limerick, v. 49, n. 1, p. 1-49, 1996. DOI: https://doi.org/10.1111/j.1744-6570.1996.tb01790.x.

KRISTOF-BROWN, A. L., LI, C. S.; SCHEIDER B. Fitting in and doing good: a review of personenvironment fit and organizational citizenship behavior research. The Oxford Handbook of Organizational Citizenship Behavior, dec. 2016. DOI:

https://doi.org/10.1093/oxfordhb/9780190219000.013.26.

KRISTOF-BROWN, A. L., ZIMMERMAN, R. D.; JOHNSON, E. C. Consequences of individual's fit at work: a meta-analysis of person-job, person-organization, persongroup, and personsupervisor fit. Personnel Psychology, Limerick, v. 58, n. 2, p. 281-342, 2005. DOI: https://doi.org/10.1111/j.1744-6570.2005.00672.x.

LAUDO TÉCNICO. Pesquisa “Melhores Empresas Para Você Trabalhar". Fundação Instituto de Administração (FIA), 2018. Disponível em: www.fia.com.br/progep. Acesso em: 26 jun. de 2018.

LEWIN, K. A dynamic theory of personality. New York, NY, US: McGraw-Hill, 1935.

LYONS, H.; O'BRIEN, K. M. The role of person-environment fit in the job satisfaction and tenure intentions of African American employees. Journal of Counseling Psychology, Washington, v. 53, n. 4, p. 387-396, 2006. DOI: https://doi.org/10.1037/0022-0167.53.4.387.

MAILHIOT, G. B. Dinâmica e gênese dos grupos. 3. ed. São Paulo: Livraria Duas Cidades, 1976.

MARRAS, J. P. Administração de recursos humanos: do operacional ao estratégico. São Paulo: Futura, 2000.

MASCARENHAS, S. A. (Org.). Metodologia científica. São Paulo: Pearson Education do Brasil, 2012.

MATITZ, Q. R. S.; BULGACOV, S. O conceito de desempenho em estudos organizacionais e estratégia: um modelo de análise multidimensional. Revista de Administração

Contemporânea, Curitiba, v. 15, n. 4, p. 580-607, jul./ago., 2011. DOI:

https://doi.org/10.1590/S1415-65552011000400003. 
MCCULLOCH; M. C.; TURBAN, D. B. Using person-organization fit to select employees for high-turnover jobs. International Journal of Selection and Assessment, Athina, v. 15, p. 6371, 2007. DOI: https://doi.org/10.1111/j.1468-2389.2007.00368.x.

MCDUFFIE, J. P. Human resource bundles and manufacturing performance: organizational logic and flexible production systems in the world auto industry. Industrial and Labor Relations Review, New York, v. 48, n. 2, p. 197-221,1995. DOI:

https://doi.org/10.2307/2524483.

MEMON, M. A.; SALLEH, R.; HARUN, H.; RASHID, R. A.; ZURINA, A. B. Person-organization fit and turnover intention: the mediating role of employee engagement. Global Business and Management Research: An International Journal, Perth, v. 6, n. 3, p. 205-209, 2014.

MUCHINSKY, P. M.; MONAHAN, C. J. What is person-environment congruence? Supplementary versus complementary models of fit. Journal of Vocational Behavior, Amsterdam, v. 31, p. 268-277, 1987. DOI: https://doi.org/10.1016/0001-8791(87)90043-1.

MURRAY, H. A. Explorations in Personality. New York: Oxford University Press, 1938.

PALLANT, J. SPSS Survival Manual. Open University Press, 2007.

PARSONS, F. Choosing a vocation. Boston, MA: Houghton Mifflin, 1909.

PERIN, M. G.; SAMPAIO, C. H. Orientação para o mercado, porte empresarial e performance. RAE-Revista de Administração de Empresas, São Paulo, v. 44, n. 3, jul./set, p. 76-88, 2004.

PERVIN, L. A. Person-environment congruence in the light of the person-situation controversy. Journal of Vocational Behavior, Amsterdam, v. 31, p. 222-230, 1987. DOI: https://doi.org/10.1016/0001-8791(87)90040-6.

PFEFFER, J. The Human Equation: Building Prots by Putting People First. Boston, MA: Harvard Business School Press, 1998.

POSTHUMA, R. A.; CAMPION, M. C.; MASIMOVA, M.; CAMPION, M. A. A high performance work practices taxonomy: integrating the literature and directing future research. Journal of Management, New York, v. 39, n. 5, p. 1184-1220, 2013. DOI:

https://doi.org/10.1177/0149206313478184.

RIBEIRO, A. L. Gestão de pessoas. São Paulo: Saraiva, 2005.

RICHARD, P. J.; TIMOTHY, M.; DEVINNEY, G. S. Measuring organizational performance: towards methodological best practice. Journal of Management, New York, v. 35, p. 718804, 2009. DOI: https://doi.org/10.1177/0149206308330560.

SCHOON, H. Person-Supervisor fit: implications for organizational stress, organizational commitment, and job satisfaction. 2008. Theses (Master of Science) - Applied Psychology, Clemson University, South Carolina do Sul EUA, 2008. 
SELDEN, S. C; SOWA, J. E. Voluntary turnover in nonprofit human service organizations: the impact of high performance work practices. Human Service Organizations Management, Leadership \& Governance, Abingdon, v. 39, n. 3, p. 182-207, 2015. DOI: https://doi.org/10.1080/23303131.2015.1031416.

SEONG, J. Y.; KRISTOF-BROWN, A.; PARK, W. W.; HONG, D. S; SHIN, Y. Person-Group fit: diversity antecedents, proximal outcomes, and performance at the group level. Journal of Management, New York, v. 41, p. 1184-1213, 2012. DOI: https://doi.org/10.1177/0149206312453738.

STEIL, A. V.; PENHA, M. M.; BONILLA, M. A. M. Antecedentes da retenção de pessoas em organizações: uma revisão de literatura. Rev. Psicologia Organizacional do Trabalho, Brasília, v. 16, n. 1, p. 88-102, mar. 2016. DOI: https://doi.org/10.17652/rpot/2016.1.542.

STEIL, A. V. Trajetória interdisciplinar formativa e profissional na sociedade do conhecimento. In A. Philippi Jr. \& A. J. Silva Neto (Orgs.), Interdisciplinaridade em ciência, tecnologia e inovação. Barueri: Manole, 2011, p. 209-228.

SU, R.; MURDOCK, C. D.; ROUNDS, J. Person-environment fit. In P. J. Hartung, M. L. Savickas, $\&$ W. B. Walsh (Eds.), APA handbooks in psychology ${ }^{\circledR}$. APA handbook of career intervention, v. 1. Foundations (p. 81-98). American Psychological Association. DOI: https://doi.org/10.1037/14438-005.

TAK, J. Relationships between various person-environment fit types and employee withdrawal behavior: A longitudinal study. Journal of Vocational Behavior, Amsterdam, v. 78, n. 2, p. 315-320, 2011. DOI: https://doi.org/10.1016/j.jvb.2010.11.006.

TIBOLA, J. A. Práticas de gestão de pessoas, alinhamento pessoa-ambiente de trabalho e performance organizacional: um estudo nas "melhores empresas para você trabalhar" no Brasil. 2012. Tese (Doutorado em Administração) - Universidade Positivo, Curitiba, 2012.

VENTURA, V. L. S.; LEITE, N. R. P. Percepção da influência da gestão estratégica de pessoas no comprometimento organizacional. Revista Pretexto, Belo Horizonte, v. 15, n. 3, p. 11-28, 2014.

VIEIRA, V. A. Moderação, mediação, moderadora-mediadora, efeitos indiretos em modelagem de equações estruturais: uma aplicação no modelo de desconfirmação de expectativas. Revista de Administração, São Paulo, v. 44, n. 1, p. 17-33, 2009.

WERBEL J.; DEMARIE, S. M. Aligning strategic human resource management and personenvironment fit: A strategic contingency perspective. Academy of Management Proceedings \& Member Directory, New York, G1-G6, 2001. DOI: https://doi.org/10.5465/apbpp.2001.6133186.

WRIGHT, P. M.; GARDNER, T. M. Theoretical and empirical challenges in studying the HR practice - firm performance relationship. In: JOLMAN, D. et al. (Eds) The New Workplace: People, Technology, and Organization. London: Wiley, 2002. 
WURSTER, K. G.; KIVLIGHAN, D. M.; FOLEY-NICPON, M. Does person-group fit matter? A further examination of hope and belongingness in academic enhancement groups. Journal of Counseling Psychology, Washington, v. 1, Apr., p. 1-22, 2020. DOI: https://doi.org/10.1037/cou0000437.

YANG, J.; PU, B.; GUAN, Z. Entrepreneurial Leadership and Turnover Intention of Employees: The Role of Affective Commitment and Person-job Fit. International Journal of Environmental Research and Public Health, Basiléia, v. 16, 2380, 2019.

DOI: https://doi.org/10.3390/ijerph16132380.

ZHANG, J. C.; LING, W. Q.; ZHANG, Z. Y.; XIE, J. Organizational commitment, work engagement, person-supervisor fit, and turnover intention: A total effect moderation model. Social Behavior and Personality: An International Journal, Perth, v. 43, n. 10, p. 1657-1666, 2015. DOI: https://doi.org/10.2224/sbp.2015.43.10.1657.

ZHEN, Y.; MANSOR, Z. D.; CHONG, C. W. Person-Organization Fit and Employees' Voluntary Turnover with the Effect of Job Satisfaction in Hotel Industry. In: Proceedings of the $\mathbf{2 0 1 9}$ 10th International Conference on E-business, Management and Economics. Beijing China, 2019. p. 61-64. DOI: https://doi.org/10.1145/3345035.3345082. 